\title{
SEMÂNTICAS ARGUMENTATIVA E ENUNCIATIVA: UMA ANÁLISE DOS OPERADORES ARGUMENTATIVOS
}

\author{
ARGUMENTATIVE AND ENUNCIATIVE SEMANTICS: AN \\ ANALYSIS OF ARGUMENTATIVE OPERATORS
}

\author{
Maria Eliane Gomes Morais ${ }^{1}$ \\ Maria da Guia Santos de França ${ }^{2}$ \\ Erivaldo Pereira do Nascimento ${ }^{3}$
}

\section{RESUMO}

Ao utilizar a língua(gem) nas diversas situações comunicativas, o usuário da língua escolhe elementos linguísticos que permitem orientar o discurso em razão de determinado objetivo. Assim, ao enunciar, o indivíduo está argumentando, uma vez que a argumentação é uma atividade inerente à natureza humana. Nesta perspectiva, Ducrot (1988) considera que a argumentação é um fenômeno inscrito na língua, que se materializa nos diferentes enunciados produzidos, por meio do repertório linguístico escolhido. Nesse repertório, muitas vezes, é possível perceber a presença de estratégias ou recursos, responsáveis pelo direcionamento do discurso, entre esses recursos destacam-se os operadores argumentativos, que além de permitir o encadeamento dos enunciados, contribuindo para a construção de efeito de sentido do texto, determinam a orientação argumentativa destes enunciados. Considerando o relevante papel desempenhado por esses operadores na construção do texto, pretendeu-se realizar um estudo teórico acerca desses operadores, sob a ótica das Semânticas Argumentativa (SA) e Enunciativa (SE), evidenciando como essas diferentes perspectivas da semântica tratam o mesmo objeto: os operadores argumentativos. Assim, na AS, o enfoque é mantido nos pressupostos teóricos de Ducrot (1987,1988); Koch (2012); Koch e Elias (2016); Nascimento (2005; 2009; 2015); e Silva (2006). Na SE, volta-se para os estudos de Benveniste (1989); Flores (2013); e Guimarães (2007; 2018). Esta pesquisa, em fase de desenvolvimento, já evidenciou que ao abordar o mesmo objeto, tanto a Semântica Argumentativa, quanto a Enunciativa, apontam para o funcionamento discursivo dos operadores, ora se aproximando, ora apresentando algumas distinções no modo de tratar esses operadores.

PALAVRAS-CHAVE: operadores argumentativos; semântica argumentativa; semântica enunciativa.

\footnotetext{
ABSTRACT

By using the language in the diverse communicative situations, we choose linguistic elements that enable to orient the discourse because of a certain objective. Thus, in enunciating, the individual is arguing, since argumentation is an activity inherent in human nature. In this perspective, Ducrot (1988) considers that the argumentation is a phenomenon registered in the language, which materializes in the different statements produced, through the linguistic repertoire chosen. In this repertoire, it is often possible to perceive the presence of strategies or resources, responsible for directing the discourse, among these resources, we can highlight the

${ }^{1}$ Doutoranda em Linguística pela Universidade Federal da Paraíba (UFPB) - Campus I - João Pessoa-PB, Brasil, lia_morais.jta@hotmail.com.

2 Mestranda em Linguística pela Universidade Federal da Paraíba (UFPB) - Campus I - João Pessoa-PB, Brasil, guia.025@hotmail.com.

3 Pós-Doutor pela Universidad de Buenos Aires-Argentina. Doutor em Letras pela UFPB. Professor da Universidade Federal da Paraíba (PROLING/PROFLETRAS/UFPB). João Pessoa-PB, Brasil, erivaldo@ccae.ufpb.br.
} 
argumentative operators, which in addition to allowing the linking of statements, contributing to the construction of text sense effect, and they determine the argumentative orientation of these statements. Considering the relevant role played by these operators in the construction of the text, we intend to carry out a theoretical study about these operators, from the perspective of the Argumentative (SA) and Enunciative (SE) Semantics, showing how these different perspectives of semantics treat the same object: argumentative operators. Thus, in SA we dwell on the theoretical assumptions of Ducrot (1987, 1988); Koch (2012); Koch and Elias (2016); Nascimento (2005; 2009; 2015); Silva (2006) and SE will turn to the studies of Benveniste (1989); Flores (2013); Guimarães (2007, 2018). This research, in the development phase, has already shown that when addressing the same object, both Argumentative and Enunciative Semantics point to the discursive functioning of the operators, sometimes approaching, sometimes presenting some distinctions in the way of treating these operators.

KEYWORDS: argumentative operators; argumentative semantic; enunciative semantic.

\section{INTRODUÇÃO}

De acordo com Bakhtin (2010), a língua pode se manifestar por meio de enunciados orais ou escritos. Para o autor, todo enunciado se considerado isoladamente é individual, mas diferentes contextos de utilização da língua elaboram seus tipos relativamente estáveis de enunciados. Isso é o que o autor denomina de gêneros do discurso (ou discursivos). Acredita-se que, além de utilizar um gênero que se adequa ao seu contexto de comunicação, o locutor, responsável pelo discurso, também utiliza elementos linguísticos que permitem uma orientação discursiva a exemplo dos operadores argumentativos.

Considerando a relevância desses elementos linguísticos, neste trabalho, buscou-se mostrar como se dá a abordagem desses operadores na Semântica Argumentativa (SA) e na Semântica Enunciativa (SE), a fim de evidenciar aspectos que se aproximam no que se refere à abordagem dos operadores argumentativos por ambas as concepções teóricas. Para tanto, utilizou-se como embasamento teórico os estudos dos seguintes autores: Benveniste (1989); Ducrot (1987,1988); Espíndola (2004); Flores (2013); Guimarães (2007 2018); Koch (2012); Koch e Elias (2016); Nascimento (2005; 2009; 2015) e Silva (2006).

Desse modo, o artigo estará organizado da seguinte maneira: inicialmente, é apresentado um panorama sobre a Semântica Enunciativa e a Argumentativa, com o intuito de definir os limites de cada uma dessas semânticas. Já que alguns teóricos, a exemplo de Koch (2012), acreditam que ambas dizem respeito a uma mesma perspectiva: o estudo dos enunciados e seus componentes linguísticos, e por isso possuem nomenclatura sinônimas. Já Guimarães (2018) considera essas semânticas como sendo duas vertentes parecidas, porém distintas, uma vez que nos estudos de Guimarães (2018) sobre SE, a argumentação é vista também na relação entre um lugar social de um "eu" para um "tu”, não apenas como algo interno à língua, como concebido na SA.

Em seguida, são apresentados conceitos e modos de abordagem dos operadores argumentativos sob a perspectiva das semânticas já mencionadas, evidenciando tal abordagem a partir de exemplos trazidos pelos próprios autores. Dessa forma, será mostrado claramente para nossos leitores como se dá a aplicação dos operadores em enunciados concretos.

Por fim, são tecidas as considerações finais, refletindo sobre o modo como a Semântica Argumentativa e a Enunciativa abordam os operadores argumentativos, evidenciando os aspectos que se aproximam e se distanciam, além disso, é apresentada a relevância dessas duas vertentes para os estudos dos fenômenos linguísticos. 


\section{Os pressupostos da semântica argumentativa}

Os estudos teóricos sobre o significado, ao contemplar uma abordagem discursiva da língua, contribuíram para que os estudiosos da linguagem voltassem sua atenção para o enunciado. Com isso, novas perspectivas de semântica surgiram, voltando-se, cada qual a seu modo, ao estudo dos sentidos dos enunciados, a exemplo da Semântica Argumentativa (SA) e Enunciativa (SE), vertentes sobre as quais o presente estudo será empreendido.

A Semântica, ao se interessar pelo significado linguístico, busca compreender como esse fenômeno se manifesta nos diferentes enunciados. Assim, cada perspectiva semântica se voltará para aspectos particulares do significado na língua. Na Semântica Argumentativa, por exemplo, o sentido de um elemento linguístico é a orientação que ele mesmo dá ao discurso, possibilitando ou não determinada continuação desse discurso. Isso porque, para Ducrot (1988) a palavra sentido é, ao mesmo tempo, significação e direção. Para o autor, o sentido está para o enunciado ${ }^{4}$, assim como a significação está para a frase ${ }^{5}$.

Como precursores da SA, Oswald Ducrot e colaboradores (1988) formularam a Teoria da Argumentação na Língua (TAL), defendendo que a argumentação está inscrita na língua, ao contrário do que apresentava a concepção tradicional de argumentação, para a qual a argumentação estava inscrita nos fatos, conforme assinala o próprio Ducrot.

Assim, é importante ressaltar que a Teoria da Argumentação na Língua (TAL) passou por algumas reformulações. Em razão dessas reformulações, a TAL possui quatro fases. A primeira diz respeito à fase do Descritivismo Radical, a segunda Descritivismo Pressuposicional, a terceira Argumentação como Constituinte da Significação e a quarta etapa, a Argumentatividade Radical. E, atualmente, Ducrot desenvolve a Teoria dos Blocos Semânticos (TBS). Em cada uma dessas fases, a concepção de argumentação e a abordagem dos operadores argumentativos também passam por reformulações.

$\mathrm{Na}$ fase do Descritivismo radical, a argumentação baseava-se em meros fatos. Nessa fase, língua e argumentação eram vistas separadamente e os conectores apenas estabeleciam relação entre os fatos. Aqui, argumentar consistia meramente no ato de descrever fatos. Assim, a argumentação era compreendida apenas por causa desses conectores que ligavam fatos. Um exemplo disso é a análise apresentada por Ascombre e Ducrot (1994, p. 200) por meio dos operadores pouco e um pouco. Segundo os autores, os sentidos que essas expressões possuem são diferentes, vejamos o exemplo:

Ex1 Pedro ha trabajado poco (Pedro trabalhou pouco)

Ex2 Pedro ha trabajado un poco (Pedro trabalhou um pouco)

Ao analisar esses exemplos, os autores percebem como ocorre a relação da língua com os fatos. Eles propunham que nos exemplos 1 e 2 a quantidade de trabalho realizada por Pedro é diferente. Isso era observado por meio dos operadores pouco e um pouco, uma vez que no primeiro exemplo a quantidade de trabalho realizada por Pedro seria menor que a quantidade realizada por Pedro no segundo exemplo.

De acordo com Nascimento (2005), as principais teses apresentadas por Ascombre e Ducrot (1994, p. 199), nessa primeira fase, são:

a) Os encadeamentos argumentativos do discurso estão fundamentados nos fatos veiculados pelos enunciados;

b) A função semântica primeira das estruturas linguísticas é a descrição dos fatos;

c) As informações veiculadas pelos enunciados resultam, por um lado, do valor semântico das frases (que é informativo) e, por outro, da aplicação eventual a este valor das leis discursivas relativas à transmissão de informação. (NASCIMENTO, 2005. p. 22).

\footnotetext{
4 "Manifestação da frase, um fragmento do discurso" (DUCROT, 1988, p. 65).

5 Definida por Ducrot (1988), como entidade linguística abstrata, que não pertence ao campo do observável.
} 
Na segunda fase da TAL, denominada Descritivismo Pressuposicional, a argumentação, conforme Nascimento, ainda era compreendida no nível factual, porém era percebida no posto, ou seja, nas informações explícitas no texto. Para Ducrot (1977), pressupor é situar o diálogo na suposição de que o outro já soubesse do conteúdo implícito no enunciado. Aqui ele retoma os exemplos 1 e 2 .

Ex1 Pedro ha trabajado poco (Pedro trabalhou pouco)

Ex2 Pedro ha trabajado un poco (Pedro trabalhou um pouco)

No exemplo 1, o posto, informação explícita, é que "a quantidade de trabalho realizada por Pedro é fraca", e o pressuposto "é que Pedro trabalhou". Já no segundo exemplo, foi observado que o posto é "Pedro realizou determinada quantidade de trabalho", enquanto o pressuposto seria "Se houve trabalho efetivado, sua quantidade foi fraca".

Observando esses exemplos, Nascimento (2005) afirma que os operadores pouco e um pouco ativam pressupostos divergentes. Nesse sentido, conforme Ducrot (1977), a argumentação estaria presente no conteúdo posto, assim os enunciados 1 e 2 orientariam conclusões diferentes, pois o conteúdo posto de 1 explicitaria a quantidade menor de trabalho realizado por Pedro, enquanto em 2 a conclusão apontaria para a existência de trabalho realizado por Pedro.

Para Nascimento (2005), a vantagem dessa fase nos estudos de Ascombre e Ducrot é o fato de que na primeira fase a argumentação dos enunciados 1 e 2 era explicada em termos de quantidade e, nessa segunda etapa, estabelecem-se potencialidades argumentativas opostas.

$\mathrm{Na}$ terceira fase da TAL, chamada de Argumentação como Constituinte da Significação, Ducrot e colaboradores começam a reconhecer e identificar valores argumentativos na língua. Nesta fase, os autores rompem com a retórica e abandonam a ideia de que a argumentação está nos fatos. Assim, afirmam que a argumentação está nas formas linguísticas e não nos elementos factuais, ou seja, os autores passam a reconhecer, neste momento, que a língua possui valores argumentativos e os conectores e operadores argumentativos começam a ser considerados elementos linguísticos que conferem e introduzem a argumentação na própria estrutura da frase, e dela, para o enunciado.

A partir disso, os autores elaboram dois conceitos muito relevantes o de escala argumentativa e classe argumentativa. A classe argumentativa, segundo o autor, consiste no conjunto de argumentos de mesmo peso que levam a mesma conclusão. Já a escala argumentativa apresenta uma relação de maior ou menor grau de argumentatividade. Descrições que serão explicitadas na próxima seção.

$\mathrm{Na}$ quarta etapa, a Argumentatividade Radical, a argumentação é inscrita definitivamente na língua e os conectores servem para especificar a força argumentativa. A noção de polifonia e de Topoi surge nessa fase.

Ducrot (1988), ao se opor à noção de unicidade do sujeito, ou seja, a ideia de que um dado enunciado possui apenas um autor, traz o termo polifonia para os estudos linguísticos. Com isso, seu intuito é afirmar que o sentido dos enunciados é, naturalmente, polifônico, ou seja, que o sentido dos enunciados é perpassado por várias vozes. Para o linguista, os fenômenos e elementos linguísticos diversos que constituem a língua são geradores de polifonia nos enunciados, a exemplo da negação, da pressuposição e da paráfrase. Nesse sentido, para provar que um enunciado pode ser constituído por várias vozes, o referido autor identifica e descreve três funções diferentes para o sujeito da enunciação: Sujeito Empírico (SE), Locutor (L) e Enunciador (E).

Conforme o linguista, o sujeito empirico "el sujeto empírico SE es el autor efectivo, el produtor do enunciado", ou seja, é aquele que produz e se responsabiliza pelo conteúdo da sua enunciação. (DUCROT, 1988, p. 16).

Já o locutor (L), não é a pessoa que produz o texto, mas aquele que se responsabiliza pelo conteúdo do dito: "para mí el locutor es el presunto responsable del enunciado, es decir la persona a quien se le atribuye la responsabilidade de la enunciación en el enunciado mismo" (DUCROT, 1988, p. 17). Um exemplo bem simples de (L) são declarações escolares que são escritas por um sujeito (SE), porém é assinada por outra pessoa que se responsabilizará pelo enunciado, nesse caso, o 
locutor. Sendo assim, o locutor pode se manifestar, no discurso, por meio das marcas de pessoa (eu, me) presentes no enunciado.

No que diz respeito aos enunciadores (E), o autor afirma que: "llamo enunciadores a los orígenes de los diferentes puntos de vista que se presentam en el enunciado. No son personas sino 'puntos de perspectiva' abstractos." (DUCROT, 1988, p. 20). Isto é, os enunciadores são os diferentes pontos de vista que o locutor apresenta em seu discurso assumindo determinadas posições em relação a esses enunciadores.

Após definir esses personagens do discurso, Ducrot propõe dois tipos de polifonia presentes nos discursos: a polifonia de locutores e a polifonia de enunciadores.

A polifonia de locutores, segundo Ducrot, afirma Nascimento (2015), ocorre quando em um mesmo enunciado identifica-se locutores distintos, possivelmente subordinados. Segundo Ducrot (1997), a polifonia de locutores é encontrada no discurso relatado direto e existem marcas linguísticas que expõem esses locutores nos enunciados como no exemplo abaixo:

Ex3 José me prometeu: Eu irei contigo.

Nesse exemplo, é possível perceber duas marcas linguísticas, pronomes me e eu, que explicitam dois locutores divergentes. $O$ me é a marca linguística que explicita o locutor responsável por todo o enunciado (L1) e o eu apresenta o locutor responsável apenas pelo segundo segmento do enunciado Eu irei contigo (L2).

Por outro lado, ao se referir à polifonia de enunciadores, Ducrot postula que num mesmo enunciado é possível observar diferentes pontos de vista e, consequentemente, a posição do locutor em relação a esses pontos de vista, "de uma maneira análoga, o locutor, responsável pelo enunciado, dá existência, através deste, a enunciadores de quem ele organiza os pontos de vista e atitudes" (DUCROT, 1997, p. 193). Ao evidenciar tais enunciadores, o locutor pode assumir diferentes posições: aprovar, assimilar ou se opor a esses enunciadores. Porém, segundo Nascimento (2009), o importante mesmo é que para Ducrot "a presença de enunciadores está intrinsecamente relacionada com o sentido do enunciado" (p. 31).

De acordo com Nascimento, a ironia, a negação, a pressuposição, o humor e os enunciados elaborados com mas $P A$ etc., são exemplos de polifonia de enunciadores. Em todos esses casos, o locutor assume as mais divergentes posições perante os enunciadores que atualiza. Conforme o linguista, o conectivo mas para Vogt e Ducrot (1980), consiste em um marcador de oposição, além disso, esse elemento linguístico expressa duas funções diferentes. Na primeira, o mas, tem a função de retificador e na segunda, que é o que nos interessa no momento, é a função de operador argumentativo, denominado pelo Ducrot como masPA. Este, como já foi mencionado, é um elemento ativador de polifonia de enunciadores. Vejamos um exemplo:

Ex4 Pedro estudou muito, mas fez péssima prova.

Nesse enunciado, segundo os postulados de Ducrot, o mas apresenta-se como operador argumentativo, mas $P A$, ativando enunciadores/pontos de vista diferentes.

E1. Pedro estudou muito

E2. Será aprovado (conclusão r)

E3. Fez péssima prova

E4. Será reprovado (conclusão não-r)

Nesse exemplo, é possível observar quatro enunciadores diferentes. Em E1 é expresso que Pedro estudou bastante, esse ponto de vista é aprovado pelo locutor (L). Já em E2, é apresentada a conclusão de que Pedro será aprovado, esse ponto de vista é rejeitado pelo locutor. Em E3, é evidenciado o ponto e vista segundo o qual Pedro não fez boa prova, que é assimilado pelo locutor. E, em E4, é apresentada a conclusão, de que Pedro será reprovado, que se opõe a conclusão de E2. Esse último ponto de vista é chamado, por Ducrot, de conclusão não-r que se opõe a uma conclusão inicial, $r$. Assim, a partir do exposto, fica evidente que nesse exemplo (L) aprova E1, rechaça E2 e assimila E3 e E4.

Nesta quarta fase da TAL, Espíndola (2004) afirma que Ducrot, reconhece que a argumentação é um elemento da língua, contida na língua e nas frases, então, a concepção dos 
operadores argumentativos é reformulada. Nesse momento da teoria de Ducrot, os operadores argumentativos não possuem a função de introduzir argumentação, pois esta já se encontra presente na língua, mas especificará qual forma tópica atualizar e que força argumentativa o enunciado assumirá no momento de sua enunciação, como visto na Teoria dos topoi.

Segundo a pesquisadora, a Teoria dos topoi "é uma teoria semântica de interpretação de enunciados ou do sentido dos enunciados" (p. 31). De acordo com Espíndola (2004), Ducrot e Ascombre "definem os topoi (...) como princípios gerais que servem de ponto de articulação entre a língua e o discurso". Nessa teoria, frase/significação, enunciado/sentido e enunciação propostos por Ducrot, assumem grande importância, afirma a autora. Além disso, aqui, os operadores argumentativos são definidos a partir da noção de topoi.

Segundo Espíndola, os operadores argumentativos, nesse momento da teoria, não buscam apenas modificar uma conclusão - como no exemplo 6 com o masP $A$ - buscam também o topos evocado. A autora cita como exemplo o uso dos operadores pouco e um pouco nos enunciados abaixo:

Ex5 João estudou um pouco, terá êxito.

Ex6 João estudou pouco, vai fracassar

Ex7 João estudou pouco, vai ter êxito

Ex8 João estudou um pouco, vai fracassar

A autora observa que 5 e 6 são enunciados obviamente aceitáveis, se for pensado no topos "o estudo conduz ao êxito", porém se for considerado o topos "o estudo não conduz ao êxito" vêse que 7 e 8 também são enunciados possíveis.

Nesse momento da teoria, Ducrot e colaboradores, segundo Espíndola (2004) também reformulam a noção de potencial argumentativo. Este deixa de ser entendido em termos de conclusões possíveis de um enunciado e passa a ser definido a partir da noção de topos. Outra grande mudança na TAL, nesse período, diz respeito ao fato de que a argumentação passou "a ser descrita em nível de enunciadores apresentados pelo discurso e não mais em nível de enunciados" (ESPÍNDOLA, 2004, p. 35).

Ducrot (1988) abandona os estudos sobre os topoi por considerá-los como elemento retórico, externo à língua, percebe, portanto que estava sendo pragmático e assume seu caráter estruturalista com a Teoria dos Blocos Semânticos (TBS), fase atual de sua teoria. A TBS assume dois princípios básicos: o abandono definitivo da noção de inferência - desde o seu início, a TAL estabeleceu que a relação entre os encadeamentos discursivos não se dá por inferência, mas por uma ordem diferente - e a interdependência semântica entre os segmentos que comportam um encadeamento argumentativo - por isso a noção de bloco semântico.

Nesse momento da teoria, Silva et al (2006) afirmam, que segundo Ducrot, a função dos conectores é a de elaborar encandeamentos argumentativos que podem ser do tipo geral $D C^{6}$ (portanto), que formam encandeamentos normativos; e do tipo $P T^{7}$ (no entanto), que geram encandeamentos transgressivos. Os autores apresentam os seguintes exemplos:

Ex09 Pedro é rico DC (portanto) é feliz.

Ex10 Pedro é rico PT (no entanto) é feliz.

Observando esses dois exemplos, percebe-se que em 09, há um encandeamento do tipo normativo, uma vez que o conector portanto orienta para a conclusão de que Pedro é feliz. Por outro lado, em 10 é expresso um encandeamento do tipo transgressor que é introduzido pelo conector no entanto.

Os pesquisadores afirmam que os enunciados 09 e 10 embora possuam sentidos distintos, expressam o mesmo bloco, o dinheiro traz felicidade.

Até então, foram apresentadas as fases, e respectivas reformulações, da Teoria da Argumentação na Língua, evidenciando as contribuições de Ducrot e colaboradores. Na próxima

\footnotetext{
${ }^{6}$ Abreviação de donc. Ver Silva et al (2006).

7 Abreviação de pourtant. Ver Silva et al (2006).
} 
sessão, a Semântica da Enunciação é apresentada, a partir de seus pressupostos teóricos e de sua relação com a Semântica Argumentativa.

\section{Construtos da semântica enunciativa}

A TAL diverge da teoria da enunciação, uma vez que Ducrot e colaboradores (1988) acreditam que a língua é fundamentalmente argumentativa. Segundo Ducrot,

(...) a enunciação é um produto da atividade do sujeito falante, quer dizer um segmento de discurso, ou, em outros termos, o que acabo de chamar de 'enunciado' (...) o que designarei por esse termo é o acontecimento constituído pelo aparecimento do enunciado. A realização de um enunciado é de fato um acontecimento histórico: é dado a existência a alguma coisa que não existia entes de se falar e que não existia antes de se falar e que não existirá mais depois. É isso que chamo de 'enunciação'. (DUCROT, 1987. p. 168).

Ducrot afirma que seu desejo é elaborar uma teoria do sentido, do enunciado de uma definição de enunciação que não esteja voltada principalmente para a noção de sujeito falante, como parece ocorrer na Semântica Enunciativa.

$\mathrm{Na}$ Semântica Enunciativa o que interessa é a investigação sobre a enunciação, na qual a análise deve considerar o ato da enunciação como um todo, elementos linguísticos, sujeitos e situações específicas. Enquanto a Semântica Argumentativa está interessada em investigar a orientação argumentativa dos enunciados.

Ainda em torno da enunciação, há de se considerar que Émile Benveniste, em seus estudos sobre a enunciação, exerceu forte influência sobre a constituição da Semântica Enunciativa. Para Benveniste (1989, p. 82), "enunciação é colocar em funcionamento a língua por um ato individual de utilização.". A semântica enunciativa, segundo o referido autor, postula que o sentido dos enunciados está na própria enunciação, ou seja, na totalidade do texto. Nesta perspectiva, Benveniste (1989, p. 84) afirma:

A enunciação é vista como um processo, um ato pelo qual locutor mobiliza a língua por sua própria conta. É o ato de apropriação da língua que introduz aquele que fala na sua fala. O produto desse ato é o enunciado, cujas características linguísticas são determinadas pelas relações que se estabelecem entre o locutor e a língua.

Para Guimarães (2007), a Semântica da Enunciação é uma semântica histórica. E, a enunciação, que é seu objeto de estudo, é o acontecimento do funcionamento da língua num espaço.

Segundo Flores (2013), a Semântica da Enunciação diz respeito a uma análise do sentido da linguagem. Para o referido autor, a Semântica Enunciativa se distancia das outras semânticas uma vez que "a análise enunciativa estuda o sentido que decorre da enunciação, mas para isso, não se restringe analisar apenas um nível linguístico (o lexical, o sintático, o morfológico, o fonológico etc.)" (2013, p. 95). Isso significa que não existe um nível a ser priorizado na análise enunciativa, já que quando o locutor enuncia "carrega em si a potencialidade de um estudo em termos de enunciação".

Assim, na Semântica da Enunciação, qualquer fenômeno, de qualquer nível, pode ser investigado na perspectiva da enunciação. O pesquisador cita, como exemplo, os estudos de Ducrot, que investiga os conectores, os operadores argumentativos; os estudos de Benveniste que investiga pronomes, verbos, advérbios, categorias gramaticais especificas índices de ostensão, formas temporais e também as funções sintáticas - de intimação, interrogação e de asserção - as modalidades e outros fenômenos.

A partir dos estudos apresentados, Flores (2013) afirma que é possível perceber que a enunciação não pode ser considerada nem um nível da língua, nem um nível da análise linguística, porém aparenta estar inscrita em todos os níveis de análise linguística, já que os fenômenos linguísticos estudados, apresentados anteriormente, são de níveis diferentes. 
Guimarães (2007, p. 19), por sua vez, afirma que “(...) os sentidos de um recorte enunciativo são os efeitos, representados no enunciado, de sua própria enunciação. Incluem-se nessa representação a orientação argumentativa e a representação do sujeito da enunciação". Segundo o autor, no enunciado, "há a representação de papéis diferentes do sujeito, ou seja, no próprio enunciado se representa a cisão fundamental do sujeito". Desse modo, a presença do sujeito na língua, parece ser fundamental para esse linguista, assim como para Benveniste:

(...) na enunciação, a língua se acha empregada para a expressão de certa relação com o mundo. A condição mesma dessa mobilização e dessa apropriação da língua é, para o locutor, a necessidade de referir pelo discurso, e, para o outro, a possibilidade de coreferir identicamente no consenso pragmático que faz de cada locutor um co-locutor. A referência é parte integrante da enunciação. (BENVENISTE, 1989. p. 84)

Ao afirmar que a enunciação possui uma função referencial, Benveniste considera que os sentidos de um enunciado possuem alguma relação com o mundo, logo, os sentidos não estariam apenas no nível linguístico, mas também no extralinguístico.

Por outro lado, essa concepção adotada por Benveniste (1989) difere totalmente dos estudos sobre a enunciação formulados por Ducrot e colaboradores (1988), uma vez que, em sua teoria da argumentação, Ducrot afirma que o sentido dos enunciados está dentro da língua e não fora dela, como propõe Benveniste.

\section{Os operadores argumentativos}

Os estudos sobre a argumentação na língua foram marcados pelas teorias desenvolvidas por Oswald Ducrot e Jean-Claude Anscombre. Esses linguistas, ao reconhecerem que a argumentação está na língua e que esta determina o direcionamento do discurso do locutor, inauguraram, na Semântica Argumentativa, a Teoria de Argumentação na Língua (TAL), descrita anteriormente.

Na TAL, entre outros conceitos, Ducrot e Anscombre (1988) apresentam a noção de operadores argumentativos evidenciando três possibilidades de funcionamento desses operadores, a saber: a) indica o princípio argumentativo e a força desse princípio; b) articulam textos maiores; c) modificam os predicados. Essa noção se afasta da concepção de que os conectivos assumem apenas uma relação lógica no enunciado, como visto nos estudos da Nova Retórica, e também do conceito apresentado pela gramática normativa de que esses operadores servem para interligar frases, orações e texto.

Conforme apontado por Espíndola (2004), os operadores são de dois tipos: os conectores argumentativos e os operadores argumentativos. O primeiro tipo diz respeito aos elementos que articulam os enunciados, de maneira a determinar a sua orientação argumentativa. Já os operadores argumentativos possuem a função de inserir argumentatividade na estrutura semântica das frases.

Ducrot e colaboradores (1988) perceberam que os operadores argumentativos são parte essencial no processo de argumentação, pois estes impõem direções no discurso, tornando possível, ou não, determinada continuação que apontará para possíveis conclusões. Foi a partir dessa constatação que Ducrot (1988) apresentou os conceitos de escala e classe argumentativa. Em ambos os conceitos, é possível identificar mais de um argumento que pode levar a uma conclusão, no entanto, na escala argumentativa há uma gradação de força dos argumentos que constitui os enunciados. A partir de Ducrot, Koch (2012, p. 30) afirma:

(...) 'uma escala argumentativa é constituída de dois ou mais enunciados que se apresentam em gradação de força crescente no sentido de uma mesma conclusão', enquanto que 'classe argumentativa é constituída de um conjunto de enunciados que podem servir de argumento para uma mesma conclusão’. (Grifos do autor).

Como exemplo de escala e classe, Koch (2012, p. 30) nos apresenta: 
Ex11 João é o melhor candidato (conclusão R)

arg.1 - tem boa formação em Economia

arg. 2 - tem experiência no cargo

arg. 3 - não se envolve em negociatas

Todos os argumentos têm o mesmo peso para levar o alocutário a concluir R, portanto, nesse exemplo, tem-se uma classe argumentativa.

Ex 12 A apresentação foi coroada de sucesso (conclusão R)

arg. 1 - estiveram presentes personalidades do mundo artístico

arg. 2 - estiveram presentes pessoas influentes nos meios políticos

arg. 3 - esteve presente o Presidente da República (argumento mais forte)

O exemplo 12, apresenta enunciados em gradação de força crescente no sentido de uma mesma conclusão, logo, tem-se uma escala argumentativa.

Assim, com base nos estudos desenvolvidos pela TAL, Koch (2012, p. 30) define operadores argumentativos como "elementos da gramática de uma língua que têm por função indicar ('mostrar') a força argumentativa dos enunciados, a direção ('sentido') para o qual apontam".

Sendo assim, ao utilizar os operadores argumentativos, o discurso é orientado, possibilitando determinadas conclusões ou não, a partir desse uso. Partindo dos conceitos de escala e classe argumentativa, Koch (2012, p. 31) apresenta os principais tipos de operadores:

a) operadores que assinalam o argumento mais forte de uma escala orientada no sentido de determinada conclusão: até, mesmo, até mesmo, inclusive; ou, então o mais fraco (ao menos, pelo menos, no mínimo), deixando, porém, subentendido que existem outros mais fortes;

b) operadores que somam argumentos a favor de uma mesma conclusão: e, também, ainda, nem, não só... mas também, entre outros;

c) operadores que introduzem uma conclusão que diz respeito aos argumentos apresentados em enunciados anteriores: portanto, logo, por conseguinte, pois, entre outros;

d) operadores que introduzem argumentos alternativos que levam a conclusões diferentes ou opostas: ou, ou então, quer... quer, seja... seja;

e) operadores que estabelecem relações de comparação entre elementos, com vistas a uma dada conclusão: mais que, menos que, tão... como;

f) operadores que introduzem uma justificativa ou explicação relativa ao enunciado anterior: porque, que, já que, pois, entre outros;

g) operadores que contrapõem argumentos orientados para conclusões contrárias: mas, embora, entre outros;

h) operadores que têm por função introduzir no enunciado conteúdos pressupostos: já, ainda, agora;

i) operadores que se distribuem em escalas opostas: um deles orienta para a afirmação total e o outro para a negação total: um pouco e pouco. Conforme Koch (2012), às vezes, tais operadores são morfologicamente relacionados.

Em Ducrot (1988), esses operadores em alguns enunciados são utilizados por um locutor (L1), gerando orientações argumentativas no discurso, de modo que permita determinadas conclusões. Além disso, a partir do uso de determinados operadores, é possível identificar posicionamentos assumidos pelo locutor responsável pelo enunciado. Em Koch e Elias (2016, p. 76), tais operadores argumentativos são elementos que fazem parte do repertório linguístico e "são responsáveis pelo encadeamento dos enunciados, estruturando o texto e determinando a orientação argumentativa". Isso nos permite concluir que esses elementos linguísticos são de grande relevância no processo de produção textual, seja escrito ou oral.

No âmbito da Semântica Enunciativa (SE), concebida como uma semântica histórica por Guimarães (2007), os operadores de argumentação são evidenciados, por meio de conceitos de polifonia e de orientação argumentativa, a partir de uma descrição semântica das conjunções. 
Assim, o referido estudioso se volta para o estudo das conjunções que são classificadas como coordenadas ou subordinadas.

Assim, ao considerar que nas construções constituídas pelas conjunções, estas têm por finalidade não somente ligar orações, mas manter e/ou opor a orientação argumentativa, e, assim, articular o argumento para uma conclusão, Guimarães (2007) evidencia o modo como os segmentos articulados se organizam em relação à enunciação. Para isso, o autor considera alguns procedimentos de análise: a) possibilidade de inversão das orações; b) possibilidade de articulação; c) alcance da negação; d) alcance da pergunta; e) o modo de encadeamento no texto; f) divisão para dois locutores numa conversa; g) divisão entonacional na frase; h) correlação dos modos verbais nas orações.

Nesta perspectiva, Guimarães (2007), analisa as conjunções - logo, pois, já que, e, além disso, não só... mas também, ou... ou, ou, $\operatorname{mas} S N$, masP $A$, embora, para que, quando e o que inicialmente, a partir dos procedimentos de análise já citados, e realiza a descrição semântica dessas conjunções nos enunciados que aparecem. Como exemplo, tem-se a descrição do conectivo logo:

Ex13 Maria comprou o carro, logo vendeu a casa.

A) Possibilidade de inversão das orações A inversão não é possível, veja-se:

Ex14 (?) Logo vendeu a casa, Maria comprou o carro.

B) Possibilidade de articulação por sobre os limites da frase Não nos parece inaceitável

Ex15 Maria comprou o carro. Logo vendeu a casa.

C) Alcance da negação

Ex16 Maria não comprou o carro, logo vendeu a casa.

Não é possível negar a frase como um todo, apenas em "comprou um carro".

D) Alcance da pergunta

Ex17 Maria comprou o carro, logo vendeu a casa?

A pergunta ou incide só sobre uma das orações ou não tem sentido.

Ex18 Maria comprou o carro. Logo vendeu a casa?

E) Modo de encadeamento no texto

Ex19 Sei que Maria comprou o carro, logo vendeu a casa.

Ambas as orações se encadeiam com "sei que"

F) Divisão para dois locutores numa conversa

Ex20 L1 - Maria comprou o carro.

L2 - Logo vendeu a casa.

L1, de forma nenhuma pode ser responsabilizado pela conclusão tirada, L2 não pode ser visto simplesmente como um eco do que diria L1, por si mesmo.

G) Divisão entonacional no interior da frase

Ex21 Maria comprou o carro/logo vendeu a casa

Ex22 (?) Maria comprou o carro logo/ vendeu a casa.

Diante da impossibilidade de (10) considera-se que cada grupo se dá num grupo entonacional.

(H) Correlação dos modos verbais nas orações

Ex23 Maria comprou o carro, logo venda a casa.

A forma imperativa só diz respeito à segunda oração.

Ex24 (?) Maria, compre o carro, logo vende a casa. (Não é possível).

Como resultado da descrição das conjunções, Guimarães (2007, p. 76) apresenta o seguinte quadro:

\section{Quadro 01}




\begin{tabular}{|c|c|c|c|c|c|c|c|c|}
\hline & $\begin{array}{c}\text { Inversão } \\
\text { das } \\
\text { orações }\end{array}$ & $\begin{array}{c}\text { Articula } \\
\text { ção por } \\
\text { sobre } \\
\text { limite } \\
\text { oracion } \\
\text { al }\end{array}$ & $\begin{array}{l}\text { Alcanc } \\
\text { e da } \\
\text { negaçã } \\
\text { o: toda } \\
\text { a frase }\end{array}$ & $\begin{array}{l}\text { Alcance } \\
\quad \text { da } \\
\text { pergunta } \\
\text { : toda a } \\
\text { frase }\end{array}$ & $\begin{array}{c}\text { Encade } \\
\text { amento } \\
\text { no } \\
\text { texto: } \\
\text { frase } \\
\text { como } \\
\text { um } \\
\text { todo }\end{array}$ & $\begin{array}{c}\text { Divisão } \\
\text { para dois } \\
\text { locutores }\end{array}$ & $\begin{array}{c}\text { Divisão } \\
\text { entonacion } \\
\text { al coincide } \\
\text { com as } \\
\text { orações }\end{array}$ & $\begin{array}{l}\text { Correlaçã } \\
\text { o de } \\
\text { modos: } \\
\text { mobilidad } \\
\text { e modal } \\
\text { correspon } \\
\text { dente }\end{array}$ \\
\hline 1- Logo & Não & $\operatorname{sim}$ & não & Não & Não & $\operatorname{sim}$ & $\operatorname{sim}$ & não \\
\hline 2-Pois & Não & não & não & Não & Não & não & $\operatorname{sim}$ & não \\
\hline 3-Já que & $\operatorname{Sim}$ & não & não & Não & Não & $\operatorname{sim}$ & $\operatorname{sim}$ & não \\
\hline 4- E & Não & $\operatorname{sim}$ & não & Não & Não & $\operatorname{sim}$ & $\operatorname{sim}$ & $\operatorname{sim}$ \\
\hline $\begin{array}{l}\text { 5- Além } \\
\text { disso }\end{array}$ & Não & $\operatorname{sim}$ & não & Não & Não & $\operatorname{sim}$ & $\operatorname{sim}$ & $\operatorname{sim}$ \\
\hline $\begin{array}{l}\text { 6- Não só... } \\
\text { mas também }\end{array}$ & Não & não & $\begin{array}{l}\mathrm{S} / \mathrm{N} \\
(\mathrm{R})\end{array}$ & $\begin{array}{c}\operatorname{sim} \\
(\mathrm{R})\end{array}$ & Sim & não & $\operatorname{sim}$ & $\operatorname{sim}$ \\
\hline 7- ou...ou & Não & não & $\begin{array}{l}\mathrm{S} / \mathrm{N} \\
(\mathrm{R})\end{array}$ & $\begin{array}{l}\text { não } \\
\text { (imp) }\end{array}$ & $\operatorname{Sim}$ & não & $\operatorname{sim}$ & $\operatorname{sim}$ \\
\hline 8 -ou & Não & $\operatorname{sim}$ & não & $\begin{array}{l}\mathrm{S} / ? \\
(\mathrm{R})\end{array}$ & $\begin{array}{l}\operatorname{sim} \\
\text { (?) }\end{array}$ & $\operatorname{sim}$ & $\operatorname{sim}$ & $\operatorname{sim}$ \\
\hline $9-$ masSN & Não & กão & não & $\operatorname{sim}$ & $\operatorname{sim}$ & não & $\operatorname{sim}$ & $\operatorname{sim}$ \\
\hline 10- masPA & Não & $\operatorname{sim}$ & não & $\begin{array}{l}\text { não } \\
\text { (imp) }\end{array}$ & não & $\operatorname{sim}$ & $\operatorname{sim}$ & $\operatorname{sim}$ \\
\hline 11- Embora & Sim & não & não & $\begin{array}{c}\text { não } \\
\text { (imp) }\end{array}$ & não & $\operatorname{sim}$ & $\operatorname{sim}$ & $\begin{array}{c}\text { não } \\
\text { (subj.) }\end{array}$ \\
\hline 12- Para que & $\operatorname{Sim}$ & $\operatorname{sim}$ & $\mathrm{S} / \mathrm{N}$ & $\mathrm{S} / \mathrm{N}$ & $\mathrm{S} / \mathrm{N}$ & $\operatorname{sim}$ & $\mathrm{S} / \mathrm{N}$ & $\begin{array}{l}\text { não } \\
\text { (subj.) }\end{array}$ \\
\hline 13- Quando & Sim & não & $\operatorname{sim}$ & Sim & $\operatorname{sim}$ & não & não & não $(\mathrm{C})$ \\
\hline 14-que & Sim & não & $\operatorname{sim}$ & $\operatorname{sim}$ & $\operatorname{sim}$ & não & กão & não (C) \\
\hline
\end{tabular}

Fonte: Guimarães (2007, p. 76)

O autor, ao sintetizar as características das conjunções analisadas, no quadro 01, conclui que a relação entre as orações pode ser descrita envolvendo dois parâmetros fundamentais: a) a articulação tema/comentário entre as orações; b) a dependência ou não entre as orações. Isto porque, do ponto de vista enunciativo, não se pode pensar numa independência absoluta entre as orações.

Guimarães (2007) se debruça sobre os aspectos semântico-pragmáticos das conjunções. Para tanto, se detém em alguns operadores argumentativos, buscando observar de que natureza argumentativa são os elementos articulados e como se constituem os papéis enunciativos desses operadores em uso. Assim, o estudioso elege, inicialmente, para essa análise, as conjunções que, quando e para que. Os enunciados que seguem (exemplos 25 e 26), do próprio autor, exemplifica o uso de que.

Ex25 Todos dizem que ele virá.

Para o autor, não parece razoável supor que o que dá ao conteúdo de 25 a característica de argumento para uma conclusão numa dada situação.

Ex26 Todos dizem que ele virá. E ele virá, sem dúvida.

Nesse caso, se há alguma força argumentativa, para Guimarães (2007), ela está ligada ao verbo dizer e não à conjunção. Esse fenômeno foi observado pelo autor, também, nas conjunções quando e para que, o que implica concluir que por não possuir força argumentativa, essas conjunções "não afetam as relações de orientação argumentativa do discurso" (GUIMARÃES, 2007, p. 94).

Ao constatar tal fato, o linguista passa a tratar só dos conectivos que parecem indicar a possibilidade de força argumentativa, por articularem elementos não dependentes enunciativamente. São eles: até mesmo, além disso /além de; ou...ou; pois, já que. Como exemplo, Guimarães (2007, p. 94) apresenta: 
Ex27 (a) Até Pedro veio.

(b) Mesmo Pedro veio.

(c) Até mesmo Pedro veio.

Nos três enunciados, conforme o pesquisador, é possível perceber uma avaliação do locutor sobre Pedro veio, ou seja, o locutor não só informa sobre a vinda de Pedro, mas objetiva que a enunciação produza um efeito no alocutário. Assim, para Guimarães, esses elementos linguísticos se constituem como argumento de uma classe argumentativa, "de tal modo que em sequências do tipo $\mathrm{X}$, mesmo $\mathrm{Y}$ os conteúdos $A$ e $B$ são argumentos de uma escala argumentativa, sendo que $B$ é argumento mais forte que $A$ para uma mesma conclusão" (p. 95). Essa noção de classe e escala argumentativa demonstrada por Guimarães (2007) tem como base os estudos de Ducrot, teórico que norteia muitas das produções de Guimarães.

Ainda em torno dos operadores, no capítulo cinco, Guimarães (2007), fundamentado em Ducrot, discute a questão da significação do uso do masP $A$ (mas) e embora, a partir dos seguintes exemplos:

Ex28 Não queria $(\mathrm{X})$, mas fiz o trabalho $(\mathrm{Y})$, porque será melhor para mim $(\mathrm{Z})$.

Ex29 Fiz o trabalho $(\mathrm{X})$, embora não quisesse $(\mathrm{Y})$, porque será melhor para mim (Z).

Nos exemplos acima, Guimarães (2007) afirma que no primeiro caso a oração Z se articula com mas $\mathrm{Y}$ e não com $\mathrm{X}$. Já no segundo, a oração $\mathrm{Z}$ se articula normalmente, com a oração X e não com embora $\mathrm{Y}$. Assim, o autor considera que "em X, mas $\mathrm{Y}$ a continuação do texto se articula com a oração que tem o mas". Ao contrário, em X, embora $\mathrm{Y}$ a continuação do texto se articula com a oração que não tem o embora (p. 110).

Nesta perspectiva, o autor apresenta as escalas argumentativas, descrevendo a orientação argumentativa em: $\mathrm{X}(\mathrm{A})$ mas $\mathrm{Y}(\mathrm{B})$, em que $\mathrm{A}$ é argumento a favor de r e $\mathrm{B}$ argumento a favor de $\sim \mathrm{r}^{8}$, sendo este argumento predominante, e $\mathrm{X}(\mathrm{A})$ embora $\mathrm{Y}(\mathrm{B})$, (embora $\left.\mathrm{Y}, \mathrm{X}\right)$, em que A é argumento a favor de $\mathrm{r}$ e $\mathrm{B}$ argumento a favor de $\sim \mathrm{r}$, sendo $\mathrm{A}$ o argumento predominante. Construções já vistas nos estudos de Ducrot (1988).

Ao discorrer sobre os operadores não só... mas também, Guimarães (2007) busca apresentar uma caracterização do sentido desses operadores, analisando algumas sequências. Como é possível observar nos seguintes exemplos:

Ex30 Isto será aprovado. Não só Paulo dará seu apoio, mas também João será convencido a fazê-lo.

Ex31 Não só isto será aprovado mas também receberá a adesão de todos.

O referido estudioso postula que na primeira sequência o não só... mas também articulam argumentos, enquanto na segunda, articulam conclusões. Assim, ele acredita que essas enunciações têm o sentido constituído por equivalência entre os elementos articulados, esses elementos ou são argumentos ou conclusões.

Assim, constata-se que Guimarães (2007) constrói seu estudo sobre os operadores de argumentação, ora seu método de análise se aproxima das noções de escala e classe argumentativa formulada por Ducrot (1988), ora se distancia uma vez que considera alguns aspectos pragmáticos ao analisar os conectivos em uso, porém vale ressaltar que o percurso feito por Guimarães é fundamentado nos estudos de Ducrot. Um aspecto que o diferencia de Ducrot é que para Guimarães (2018, p. 97) "a argumentação se dá como engajamento de um lugar que enuncia uma relação entre X e Y”, portanto, ao considerar esse lugar social, Guimarães se distancia da concepção de que a argumentação está na língua, conforme preconizou Ducrot (1988).

\footnotetext{
8 Guimarães (2007) adota a mesma concepção apresentada por Ducrot (1987), para esse símbolo. Assim, lê-se conclusão não-r.
} 


\section{CONSIDERAÇÕES FINAIS}

Ao realizar o levantamento teórico sobre o modo como os operadores argumentativos são abordados nas Semânticas Argumentativa e Enunciativa, foi possível perceber as relevantes contribuições que essas semânticas conferem aos estudos desses elementos linguísticos, principalmente no que se refere à compreensão do funcionamento discursivo dos operadores nos enunciados que serviram de exemplo no decorrer das exposições teóricas.

$\mathrm{Na}$ Semântica Argumentativa, foi constatado que os operadores argumentativos assumiram diferentes funções, ao longo das reformulações teóricas de Ducrot, desempenhando, inicialmente, apenas o papel de interligar os fatos, depois assumindo a função de conferir e introduzir a argumentação na frase e, por fim, configurando-se como elementos linguísticos que têm por função indicar a força argumentativa dos enunciados, conceito adotado pelos estudiosos da SA.

Ainda em se tratando dos operadores argumentativos, Ducrot, ao observar o comportamento do "mas", trouxe significativas contribuições para que se possa entender o funcionamento desse operador e sua implicação em determinado enunciado, como demonstra o autor em sua análise do mas $\mathrm{P} A$, ativador de polifonia de enunciadores, que permite estabelecer uma oposição entre a conclusão $r$ e a conclusão não-r, a partir de pontos vistas expressos no próprio enunciado. Assim, em seus estudos sobre os operadores argumentativos, Ducrot evidencia o funcionamento desses elementos como responsáveis por direcionar o discurso a determinadas conclusões.

Nesta perspectiva, Koch (2012) também organiza os operadores argumentativos, a partir do funcionamento discursivo que cada um desempenha, o que permite compreender como esse funcionamento pode ser identificado e analisado no discurso.

Na Semântica Enunciativa, especificamente, a partir de Guimarães (2007), foi averiguado que a abordagem das conjunções, denominadas de operadores de argumentação pelo autor, recebe um tratamento que tem como base os estudos de Ducrot, ao tratar da noção de escala e classe argumentativa e de polifonia. Porém, as análises empreendidas adotam também procedimentos diferentes, que, inclusive, podem ser utilizados para descrição do funcionamento dos operadores, como faz Guimarães (2007).

No entanto, o que Guimarães (2007) parece ter como objetivo, ao analisar o uso das conjunções nos enunciados, é evidenciar que as relações de dependência e não dependência, classificadas pela gramática normativa, como subordinada e coordenada, respectivamente, são questionáveis. Para Guimarães (2007), as conjunções podem funcionar articulando tema e dependência ou não entre as orações, já que do ponto de vista enunciativo não se considera independência total entre as orações.

Além disso, ao analisar o funcionamento das conjunções, Guimarães (2007) considera aspectos pragmáticos, quando busca descrever os papéis enunciativos das conjunções estudadas, aspectos esses que não foram de interesse de Ducrot (1988). É nesse tipo de abordagem dos operadores de argumentação que a SE parece se distanciar da SA, no entanto, o que não se pode deixar considerar é que tanto a SE, quanto a SA, evidenciam a relevância dos operadores e seu funcionamento semântico-discursivo a partir de sua presença no enunciado.

\section{REFERÊNCIAS}

BAKHTIN. Mikhail Mikhailovich. Estética da criação verbal. Tradução de Paulo Bezerra. $5^{\text {a }}$ edição. São Paulo: Martins Fontes, 2010.

BENVENISTE, E. O aparelho formal da enunciação. In: Problemas de Linguística Geral II. São Paulo: Pontes, 1989.

DUCROT, Oswald. O dizer e o dito. Campinas, São Paulo: Pontes, 1987.

. Polifonía y argumentación. Universidade del Valle - Cali, 1988.

ESPÍNDOLA, Luciene. A entrevista: um olhar argumentativo João Pessoa: ADUFPB, 2004. 
GUIMARÃES, Eduardo R.J. Texto e Argumentação. Um estudo de conjunções do português. Campinas, SP: Pontes, 2007.

. Semântica: enunciação e sentido. Campinas, SP: Pontes, 2018.

JUNIOR, F, C.; BASSO, R. Semântica, semânticas: uma introdução. São Paulo: Contexto, 2013.

KOCH, Ingedore G. Villaça. A Inter-ação pela linguagem. São Paulo: contexto, 2012.

; ELIAS, Wanda Maria. Escrever e argumentar. São Paulo: Contexto, 2016.

NASCIMENTO, Erivaldo Pereira do. Jogando com as vozes do outro: a polifonia - recurso modalizador - na notícia jornalística. 2005. Tese (Doutorado em Letras) - Centro de Ciências Humanas, Letras e Artes, Universidade Federal da Paraíba, João Pessoa, 2005.

Jogando com as vozes do outro: argumentação na notícia jornalística. João Pessoa: Editora Universitária da UFPB, 2009.

A polifonia nos gêneros acadêmicos e formulaicos: a construção de sentidos a partir da evocação da palavra alheia. Porto Alegre: Revista Letras de Hoje, v. 50. 2015.

SILVA, Carmem Luci da Costa; TOLDO, Cláudia Stumpf; BARBISAN, Leci Borges; MARQUARDT, Lia Lourdes; MACHADO, Rejane Flor. Enunciação e argumentação no discurso. Cadernos de Pesquisa em Linguística. Porto Alegre, Vol.2., nº.1., p. 102-111, novembro de 2006. 